\title{
DEVELOPING MUTANT SUNFLOWER LINES (Helianthus annuus L.) THROUGH INDUCED MUTAGENESIS AND STUDY OF THEIR COMBINING ABILITY
}

\author{
Encheva, J. ${ }^{*}$ and Shindrova, P.
}

Dobroudja Agricultural Institute, General Toshevo 9520, Bulgaria

Received: June 13, 2010

Accepted: March 15, 2011

\begin{abstract}
SUMMARY
Immature sunflower (Helianthus annuus L.) zygotic embryos of sunflower double haploid fertility restorer line $381 \mathrm{R}$ were treated with ultrasound before planting to embryo culture medium. Some mutant plants were isolated and self-pollinated for several generations. New sunflower forms with inherited morphological, biochemical and phytopathological changes were obtained through selection and self-pollination. The genetic changes included 12 morphological and biochemical agronomic traits. In our study the plant height, leaf petiole length, 1000-seed weigh, as well as oil content in them were most unstable, based on all investigated characteristics. In comparison to the control $381 \mathrm{R}$, decreasing in the mean value of the indexes was registered for $66.7 \%$ of the total number of characteristics and vice verse, significant increasing for the number of branches and oil content in seed i.e., 16.7\%. Stability after induced mutagenesis was demonstrated by the characteristic number of leaves. This index was not affected by the changes in climatic conditions. Mutation for resistance to Plasmopara halstedii (Farl.) was obtained from the susceptible Bulgarian control line $381 \mathrm{R}$. Reduction of plant height, increasing oil content in seeds, very good combining ability, resistance to Plasmopara halstedii, as well as to the parasite Orobanche cumana of the new mutant lines is a desirable combination in the breeding program of sunflower. Hybrids No. 15, No. 16 and No. 17, developed with the participation of lines No. 97, No. 100 and No. 101 considerably exceeded the mean standard (commercial hybrids San Luka, Maritza and Mura) by seed and oil yield. Ultrasound in sunflower can be successfully used to develop new mutant lines useful for heterosis breeding.
\end{abstract}

Key words: Helianthus annuus L., immature zygotic embryos, ultrasound, mutagenesis, new breeding material, resistance, Plasmopara halstedii (Farl.), Orobanche cumana

* Corresponding author: e-mail: july_262002@yahoo.com 


\section{INTRODUCTION}

Development of new sunflower hybrids possessing high resistance to diseases and new oil and protein qualities depends on the availability of suitable genetic resources.

A new approach, which is a combination of induced mutagenesis and embryo culture method, provides an additional possibility to enrich genetic variability in this crop and accelerate the selection process. It is easily applicable and has a considerable practical value because of the rich genetic variation which it may induce.

Induced mutagenesis, both physical and chemical, proved favourable for mutation induction in tissue cultures. Encheva et al. (1993, 2002, 2003, 2003) reported statistically significant changes in morphological characters of plants regenerated from immature zygotic embryos of sunflower, independently and in combination with gamma irradiation or ultrasound. Positive results were obtained when induced mutagenesis and tissue cultivation were combined appropriately in tomato (Gavazi et al., 1987), in maize, banana and plantain (Novak et al., 1988, 1990), many crops (Mike et al., 1990, 1991), in potato (Ahloowalia, 1990), wheat (Cheng et al., 1990), oil crops (Ashri, 1993) and in rice (Maluszynski et al., 1994).

Although sunflower breeding has been very successful throughout the last decades, a number of aims remain to be achieved, e.g., resistance to downy mildew and to the parasite broomrape. However, these efforts are obviously limited by the narrow genetic base of a commercial sunflower which has to be enlarged by the utilization of wild species, mutagenesis or tissue culture.

Downy mildew, caused by Plasmopara halstedii (Farl.) is one of the main diseases in most sunflower growing areas in the world. Its control is presently realized by breeding of resistant varieties and hybrids, or by pre-sowing dressing of seeds with metalaxyl-containing fungicides. In recent years a number of authors have reported the occurrence of new, more virulent races of the pathogen which have overcome the resistance of the varieties and hybrids introduced into practice (Maširević, 1992; Mouzeyar et al., 1994; Viranyi, F., Gulya, T., 1996). According to other authors these races demonstrate resistance to the fungicides used up to now (Albourie et al., 1998; Molinero- Ruiz et al., 2002; Baldini et al., 2006). The facts mentioned above show that sunflower downy mildew forms new races in the process of its evolution which imposes the necessity of making systematic studies of the resistance to downy mildew, as well as breeding resistant lines and hybrids.

Broomrape is a parasite on roots of sunflower plants and causes serious damages to sunflower production (Škorić, 1994). Losses may be severe, near 100\% in parts or even entire fields under extreme circumstances. Broomrape presents a serious problem to sunflower production in Bulgaria, as well. This leads, on one hand, to considerable overt losses and yield decrease, as well as worsened quality of the obtained produce on the other (Shindrova et al., 1998). Taking into account 
the limited distribution of parasites and decreasing the losses it causes, it would be preferable to develop new lines resistant to the broomrape.

The aim of this study was:

a) to develop variable $\mathrm{R}$ lines of sunflower with higher oil content through induced mutagenesis of immature zygotic embryos in initial genotype 381 $\mathrm{R}$, and

b) to evaluate new genetic material for resistance to Plasmopara halstedii (Farl.)-race 330 and to the local population of the parasite Orobanche cumana (races A-E) and

c) to carry out biometric investigations on the new lines $\left(R_{5} M_{5}\right.$ generation), and

d) to study combining ability of some of the new R lines produced.

\section{MATERIAL AND METHODS}

A number of the experiments were carried out in laboratories, and others on the trial field of Dobroudja Agricultural Institute-General Toshevo. The morphological and biochemical traits of new mutant lines and the control genotype were studied during the years 2004-2006.

\section{A - Development of mutant lines}

The Bulgarian double haploid fertility restorer line $381 \mathrm{R}$, which is highly homozygote, was used as donor material. The main requirement for the initial plant material used according to the methods of embryo culture, in combination with ultrasound, is to be genetically pure, i.e., homozygotic to the highest possible degree. Therefore, the control line $381 \mathrm{R}$ with very good morphological uniformity was chosen as the initial material for induced mutagenesis.

The plants were grown in the field and were hand-pollinated. The isolated immature zygotic embryos (11-13 days old) were treated with ultrasound using the dose $25.5 \mathrm{~W} / \mathrm{cm}^{2}$ for $1 \mathrm{~min}$ and $3 \mathrm{~min}$, respectively, before planting on the nutrition medium M for further growing (Azpiroz et al., 1988): 1/2 MS (Murashige \& Skoog, 1962) macro salts, MS micro salts, B5 vitamins (Gamborg et al., 1968), $20 \mathrm{~g} / 1$ sucrose, pH-5.7. Immature embryos were aseptically isolated and sterilized under the following conditions: 1) $1 \mathrm{~min}$ in 95\% ethanol; 2) 15 min in bleaching solution $(2.7 \% \mathrm{Cl}) ; 3)$ followed by several washings in sterile distilled water. Sixty zygotic embryos were planted for each variant. The conditions for cultivation were: $25^{\circ} \mathrm{C}$, $16 / 8 \mathrm{~h}$ photoperiod for one week. The plants which formed roots were transferred to soil and were further grown and self-pollinated in greenhouse conditions.

\section{B - Field experiments}

\section{Biometric evaluation of control line $381 \mathrm{R}$ and mutant lines $97 \mathrm{RM}, 98 \mathrm{RM}$, 99 RM, $100 \mathrm{RM}$ and $101 \mathrm{RM}$}

As a result of long-term selfing and individual selection, new sunflower mutant lines were produced in $\mathrm{R}_{5} \mathrm{M}_{5}$ generation. The main criterion for selection was high 
oil content in seeds and resistance to downy mildew and broomrape. The lines were investigated with regard to some main characteristics concerning sunflower breeding. Biometric studies of plants were carried out in each generation.

The biometric evaluation of the control genotype and newly developed mutant lines were made on 10 plants for each individual year, and included 12 main agronomic traits, such as oil content in seeds, 1000-seed weight, plant height, leaf width, leaf length, number of leaves, leaf petiole length, head diameter, number of branches, length of branches, diameter of branch head and stem diameter. 1000 seed weight ( $g$ ) was determined on three samples of 50 seeds per head each. The control data were collected from plants of the original line $381 \mathrm{R}$, which was grown in the field together with the mutant plants.

\section{Biochemical analysis}

Nuclear-magnetic resonance (Newport Instruments Ltd., 1972) was used to determine the oil content of dry seeds from the materials included in the study.

\section{Hybridization}

To determine the combining ability of newly developed sunflower lines $97 \mathrm{RM}$, $100 \mathrm{RM}$ and $101 \mathrm{RM}$ the sterile analogues of the Bulgarian selfed lines 1672 and 1676 were used. The standards of comparison of new hybrids No. 2, No. 5, No. 6 , No. 15, No. 16 and No. 17 were the Bulgarian commercial hybrids San Luka, Maritza and Mura. The obtained hybrid combinations were tested during 2006 in the breeding fields of DAI using the block-design method, in three replications, the area of each replication being $10 \mathrm{~m}^{2}$ (Barov and Shanin, 1965).

\section{C - Phytopathological evaluation}

The phytopathological evaluation of the control genotype $381 \mathrm{R}$, the obtained mutant lines, as well as hybrids, was performed with regard to downy mildew Plasmopara halstedii (Farl.) Berlese \& de Toni - race 330 and the local Orobanche population (race A-E) in the Sunflower Phytopathology Laboratory during 2005-2006. Taking into account the resistance to downy mildew, the method suggesting by Gulya et al. (1991) was used. The evaluation of hybrids and 50 plants from each lines was carried out according to standard methodologies: $0 \%=\mathrm{S}$ (sensitive); $100 \%=\mathrm{R}$ (resistant).

Broomrape resistance was evaluated under greenhouse conditions according to Panchenko (1975), slightly modified to local conditions. Broomrape resistance was calculated as the percentage of non-infected plants. The reaction of 50 plants from each genotype was recorded using the following scale: $0-100 \%$.

\section{Statistical analysis}

The developed new mutant lines were analyzed statistically with regard to the agronomic traits such as oil content in seeds, 1000 seed weight, plant height, leaf 
width, leaf length, number of leaves, leaf petiole length, head diameter, number of branches, length of branches, diameter of branch head and stem diameter.

The following statistical analyses were performed: a) variance analysis using the following model: $\mathrm{Y}_{\mathrm{ijk}}=\mu+\alpha_{\mathrm{i}}+\beta_{\mathrm{j}}+(\alpha \beta)_{\mathrm{ij}}+\varepsilon_{\mathrm{ijk}}$ (Everett, 1984), b) student's T-test, c) cluster analysis by Euclidean linkage distances (Elliott et al., 1982). Analysis of the experimental data was made using the statistical package BIOSTAST 6.0.

\section{RESULTS AND DISCUSSION}

\section{Evaluation according to quantitative traits in mutant lines $97 \mathrm{RM}, 98 \mathrm{RM}$, 99 RM, 100 RM and 101 RM}

The aim of this study was to investigate some agronomic traits of sunflower mutant lines, produced through induced mutagenesis. The lines 97 RM, 98 RM, 99 RM, $100 \mathrm{RM}$ and $101 \mathrm{RM}$ (Figures 1-3) originating from double haploid line $381 \mathrm{R}$ (Figure 1) were selected due to their good combining abilities or statistically significant morphological and biochemical changes.

The differences in the highest level of statistical significance were established in the genetic potential of the plant height, head diameter, leaf width, leaf length, stem diameter, number of branches, length of branches, diameter of branch head, leaf petiole length, 1000 seed weight and oil content in seeds (Table 1).

Table 1: Mean of square of the studied indices

\begin{tabular}{|c|c|c|c|c|}
\hline Indices & MSA & MSB & MSA $\times$ B & MSE \\
\hline Plant height & $2811.79 * \star \star$ & $674.02^{\star \star \star}$ & $72.42^{\star \star \star}$ & 18.18 \\
\hline Head diameter & $20.78^{\star \star \star}$ & $16.96^{\star \star \star}$ & $1.62^{\star \star}$ & 0.69 \\
\hline Leaf length & $51.25^{\star \star \star}$ & 0.65 & $12.72^{\star \star \star}$ & 2.65 \\
\hline Leaf width & $32.50 * * \star$ & $20.36^{\star \star \star}$ & $13.34^{* * *}$ & 2.08 \\
\hline Stem diameter & $19.02^{\star \star \star}$ & $89.49 * * *$ & $10.90^{* \star *}$ & 3.36 \\
\hline Number of brunches & $766.49 * * *$ & $196.55^{\star \star *}$ & $115.56^{* * *}$ & 5.28 \\
\hline Length of branches & $915.77^{\star * *}$ & $862.67^{\star \star *}$ & $186.53^{* * *}$ & 26.11 \\
\hline Number of leaves & 70.89 & 661.85 & 113.96 & 9.41 \\
\hline Diameter of branch head & $17.16^{\star \star \star}$ & $1.91 *$ & $1.39 * \star$ & 0.47 \\
\hline Leaf petiole length & $46.41^{\star \star *}$ & $11.17^{\star * \star}$ & $9.87^{\star \star \star}$ & 1.37 \\
\hline 1000 seed weight & $4843.86^{\star \star *}$ & $380.87^{\star * *}$ & $25.92^{\star *}$ & 9.44 \\
\hline Oil content in seed & $214.82^{\star \star *}$ & $116.64^{\star \star *}$ & $14.22^{\star \star \star}$ & 3.12 \\
\hline df & 5 & 2 & 10 & 162 \\
\hline
\end{tabular}

A-genotype, B - environmental conditions , * - statistical significance by $\mathrm{p}=0.05$,

$\star \star$ - statistical significance by $p=0.01,{ }^{* \star \star}$ - statistical significance by $p=0.001$

The statistically significant changes abouthe character of plant height were towards decrease of the mean value from 6.47 to $23.3 \mathrm{~cm}$, according to the control $381 \mathrm{R}$ (Table 2). Plant height is one of the morphological indexes most often investigated in cultural sunflower, it is consider a quantitatively inherited character. Breeding to improve stem strength is a major objective of researchers of sunflower. 


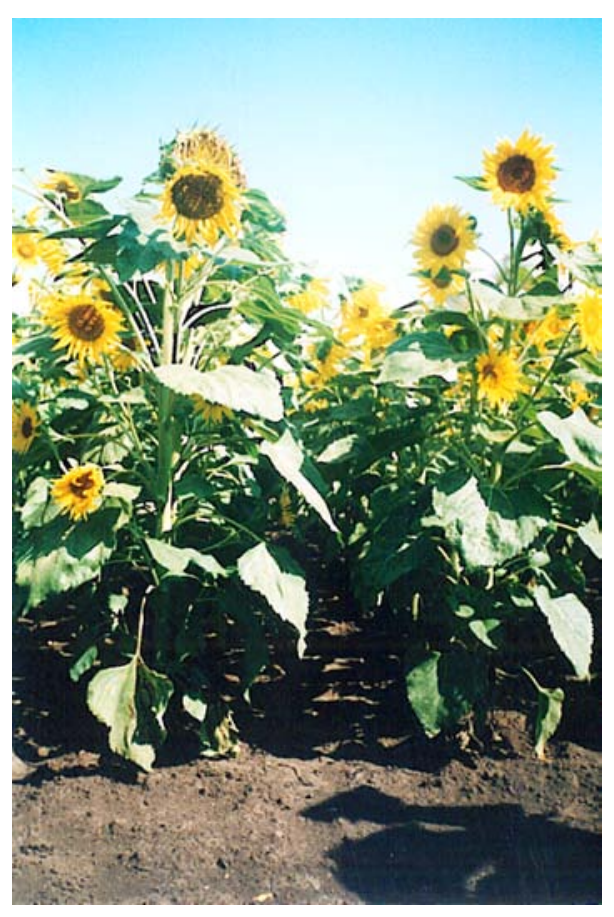

Figure 1: Control line $381 R$ and mutant line $97 \mathrm{RM}$
Decrease in the plant height has been reported in using the direct organogenesis method in combination with gamma irradiation (Encheva et al., 1993, 2002) and in somaclonal lines (Encheva et al., 1993, 2002, 2003). Novak et al. (1988) reported plant height reduction after treatment of immature zygotic embryos of maize with 5 Gy.

In this study reduced plant height with similar number of leaves showed that the internodes lengths were reduced in mutant lines.

According to Miller and Hammond, 1991 the additional component of genetic effects control reduced the height with similar number of leaves in sunflower ranged from 48 to $71 \%$, while the dominant component ranged from 3 to $16 \%$. Stem breakage due to adverse growing conditions can significantly reduce yields in some years. Altering plant architecture by reduced height may lead to increased yield, owing to the improved standing ability of the plants.

Table 2: Effect of ultrasound treatment on some morphological and biochemical characteristics of mutant lines, produced through induced mutagenesis of immature zygotic embryos from genotype 381 R. Harvest years 2004-2006, average data

\begin{tabular}{|c|c|c|c|c|c|c|c|}
\hline Traits & $\begin{array}{c}\text { Control } \\
\text { line } 381 \mathrm{R}\end{array}$ & $\begin{array}{c}\text { Line } 97 \\
\text { RM }\end{array}$ & $\begin{array}{c}\text { Line } 98 \\
\text { RM }\end{array}$ & $\begin{array}{l}\text { Line } 99 \\
\text { RM }\end{array}$ & $\begin{array}{l}\text { Line } 100 \\
\text { RM }\end{array}$ & $\begin{array}{l}\text { Line } 101 \\
\text { RM }\end{array}$ & $\begin{array}{l}\text { LSD } \\
(5 \%)\end{array}$ \\
\hline Plant height $(\mathrm{cm})$ & 126.00 & $118.83-c$ & $119.60-\mathrm{c}$ & $102.83-\mathrm{C}$ & $103.30-c$ & $107.67-c$ & 2.10 \\
\hline Number of leaves (no) & 24.00 & $30.00+c$ & 26.00 & 24.00 & $28.00+c$ & 24.00 & 1.56 \\
\hline Leaf width $(\mathrm{cm})$ & 16.65 & $15.00-\mathrm{c}$ & 17.10 & 13.93-c & $14.30-\mathrm{c}$ & $14.30-\mathrm{c}$ & 0.83 \\
\hline Leaf length $(\mathrm{cm})$ & 19.53 & $16.83-c$ & 18.40 & 16.83-c & $17.40-\mathrm{c}$ & $17.97-\mathrm{c}$ & 0.68 \\
\hline Petiole length (cm) & 14.27 & $11.50-\mathrm{c}$ & $11.73-\mathrm{c}$ & $11.00-c$ & $10.83-c$ & $11.93-\mathrm{c}$ & 0.56 \\
\hline Stem diameter $(\mathrm{mm})$ & 21.33 & 20.13 & 19.97-c & 19.80-c & 19.97-c & $19.47-c$ & 0.87 \\
\hline Head diameter $(\mathrm{cm})$ & 12.70 & 12.57 & 12.23 & $11.63-\mathrm{c}$ & $11.30-\mathrm{c}$ & $10.53-c$ & 0.41 \\
\hline Number of branches (no) & 11.00 & 11.00 & $13.00+c$ & $20.00+c$ & $20.00+c$ & $22.00+c$ & 1.13 \\
\hline Length of branches $(\mathrm{cm})$ & 30.70 & $21.43-\mathrm{c}$ & $18.20-\mathrm{c}$ & 31.87 & 28.33 & 29.40 & 2.49 \\
\hline Diameter of branched head $(\mathrm{cm})$ & 6.17 & 5.37-c & 5.80 & $4.90-\mathrm{c}$ & $4.43-\mathrm{c}$ & $4.27-c$ & 0.31 \\
\hline Oil content in seed (\%) & 40.14 & $42.67+c$ & $43.36+c$ & $45.72+c$ & $47.15+c$ & $46.51+c$ & 0.84 \\
\hline 1000 seed weight $(\mathrm{g})$ & 62.45 & $36.65-c$ & 40.50-c & 30.90-c & 29.72-c & 28.91-c & 1.58 \\
\hline
\end{tabular}

$\mathrm{a}, \mathrm{b}$ and $\mathrm{c}=$ significant differences at levels $0.05,0.01$ and 0.001 , respectively 
With the exception of line $98 \mathrm{RM}$, a significant reduction in leaf size was registered in all studied lines. A considerable decrease of the mean value of both indexes was observed in line $99 \mathrm{RM}$ (13.9 cm leaf width and $16.8 \mathrm{~cm}$ leaf length in comparison to $16.5 \mathrm{~cm}$ and $19.5 \mathrm{~cm}$, respectively, in the variant used for checking).

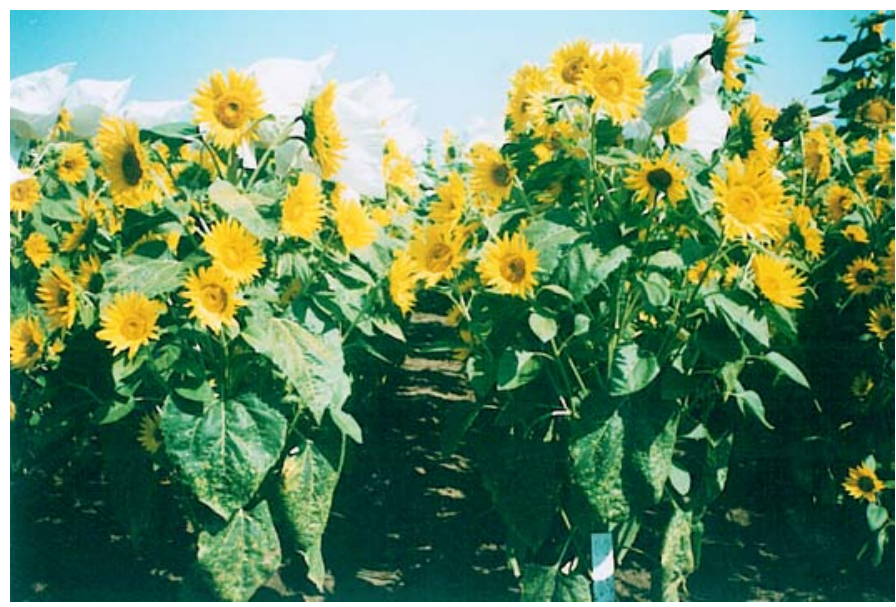

Figure 2: Mutant lines 99 RM and $100 \mathrm{RM}$

In the lines $98 \mathrm{RM}, 99 \mathrm{RM}, 100 \mathrm{RM}$ and $101 \mathrm{RM}$ a significant increase of the number of branches (from 2 to 11) was registered. Regarding the length of branches, the observed statistical difference was only in the direction towards decrease. The statistical reduction in comparison to the control ranged from 9.3 to $12.5 \mathrm{~cm}$. Negative changes of 1000-seed weight mean index value was registered in all investigated lines with the highest degree of significance. The decrease was from 22.0 to $33.5 \mathrm{~g}$.

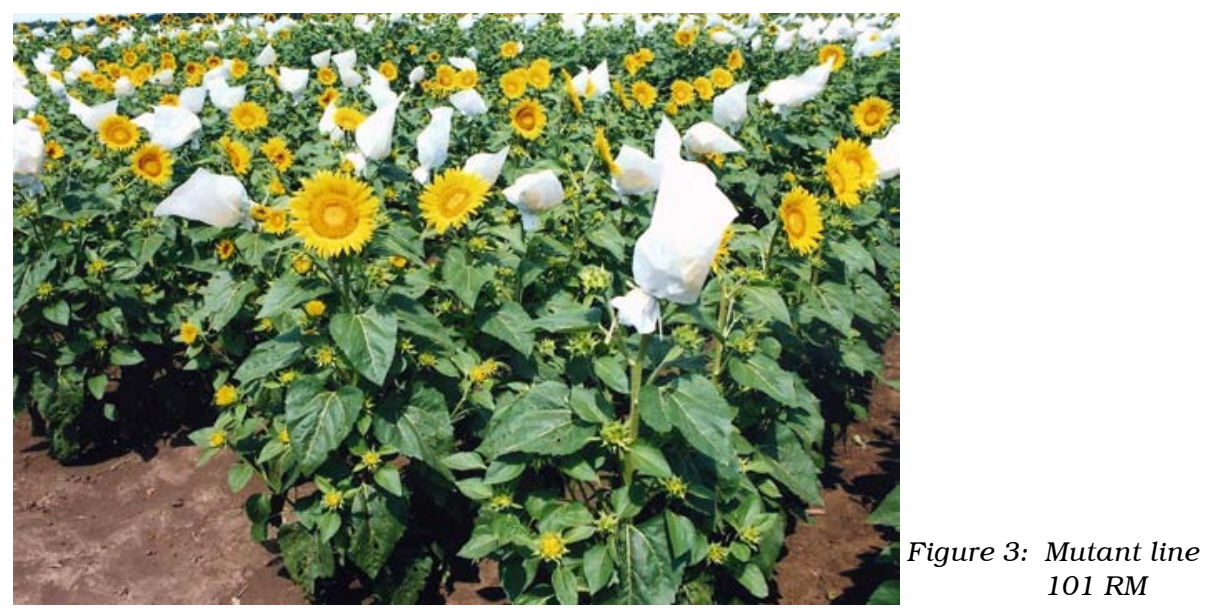

Oil content in seed is one of the most important agronomic indexes. A significant increase of $2.5 \%$ to $7 \%$ was noticed in all mutant lines. One of the aims of our 
study was to develop variable $\mathrm{R}$ lines from sunflower with higher oil content through induced mutagenesis in initial genotype $381 \mathrm{R}$. The increased oil content of the mutant restorer lines is a valuable change with significant practical importance for the sunflower breeding programme. The data presented in this study confirmed the conclusions made previously that ultrasound in $\mathrm{R}$ lines (Encheva et al., 2003) and in B lines (Encheva et al., 2004) leads to genetically increased oil content in seeds.

The reduction of plant height, increased number of branches, as well as shorter branches, lead to the development of lines 98 RM, 99 RM, 100 RM and 101 RM with changed architecture.

In our study the plant height, leaf petiole length, 1000-seed weight and oil content in seeds were most unstable, based on all investigated characters. The highest number of changes in indexes (10 from 12) was observed in lines 99 RM, 100 RM and 101 RM i.e., 83.3\% of the total number of characteristics. Based on all 12 agronomic characteristics investigated, it can be determined that the reduction in the mean value ( 8 from 12 ) in comparison to the control $381 \mathrm{R}$ was observed for plant height, leaf width, leaf length, leaf petiole length, diameter of branch head, stem diameter, head diameter, length of branches and length of branches i.e., $66.7 \%$ of the total number of traits. On the contrary, positive significant differences were registered only for a number of branches and oil content in seeds, i.e., $16.7 \%$ of the total number of characteristics. Stability after induced mutagenesis of immature zygotic embryos was demonstrated by the characteristic number of leaves.

It can be concluded that the observed changes in the mutant lines are deviations in the values of the most important agronomic indexes, but new characteristics in sunflower were not observed.

Factor B (environmental conditions) had a significant effect on a large part of the traits such as: plant height, head diameter, leaf width, stem diameter, number of branches, length of branches, the diameter of branch head, petiole length, 1000seed weight and oil content in seeds (Table 1). It was found that the characteristic leaf length and number of leaves were stable and were not affected by the changes in the climatic conditions.

The interaction of the two investigated factors (A and B) was highly significant for the indices plant height, head diameter, leaf width, leaf length, stem diameter, number of branches, length of branches, diameter of branch head, leaf petiole length, 1000 seed weight and oil content in seed (Table 1). The lack of statistical significance of the investigated factors, as well as genotype $\times$ environment $(\mathrm{G} \times \mathrm{E})$ interaction, was established only for a certain number of leaves.

\section{Cluster analysis for agronomic and morphological traits}

\section{Investigation on the Euclidean distance between control line $381 \mathbf{R}$ and mutant lines 97 RM, 98 RM, 99 RM, 100 RM and 101 RM}

Cluster analysis was carried out calculating the Euclidean distances between the investigated lines. The dendrogram of phytopathological, morphological and biochemical classification resulted in the differentiation of the control genotype and 
the new mutant lines into third main clusters. Figure 4 presents the genetic relation between mutant lines and the control genotype $381 \mathrm{R}$ with regard to Plasmopara halstedii and Orobanche cumana resistance and on the calculated mean arithmetic values from 12 characteristics during a 3-year period of investigation and their variations during one year. In the constructed scheme three main clusters can be recognized-control line $381 \mathrm{R}$, the second lines $97 \mathrm{RM}$ and $98 \mathrm{RM}$, and the third lines 99 RM, 100 RM and 101 RM. The dendrogram shows a big Euclidean distance between the new developed lines and the check line. The big distance of mutant lines and control line $381 \mathrm{R}$ was due to the fact that they differ mainly with resistance to the Plasmopara halstedii. The new mutant lines have larger number of branches and increased oil content. On the other hand, the lines possess shorter and thicker stem, as well as shorter branches and leaf petiole.

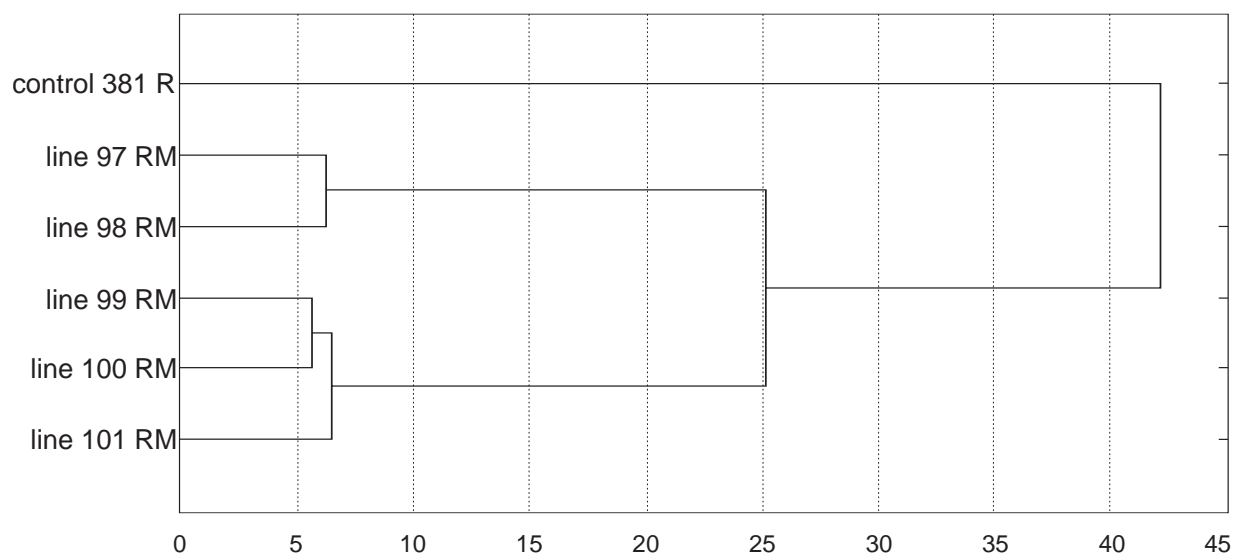

Figure 4: Degree of similarity between control line $381 R$ and mutant lines $97 R M, 98 R M$, $99 \mathrm{RM}, 100 \mathrm{RM}$ and $101 \mathrm{RM}$

The highest degree of similarities between lines $99 \mathrm{RM}$ and $100 \mathrm{RM}$ and between $97 \mathrm{RM}$ and $98 \mathrm{RM}$ was demonstrated by small Euclidean distances. That may be explained by similar resistance to the parasite broomrape and downy mildew, similar morphological traits and reaction to the factors of environment. The morphological classification separated line $101 \mathrm{RM}$ from the most narrowly formed group.

\section{Evaluation of the sunflower mutant lines and hybrids for resistance to downy mildew and local broomrape population}

Downy mildew of sunflower (Helianthus annuus L.) is caused by the parasite Plasmopara halstedii. According to the last nomenclature system there are 10 downy mildew races currently existing in the world, as follows: 100, 300, 310, 330, 700, 703, 710, 711, 730 and 770 (Tourvieille et al., 2000).

Since 2005 the race 330 in North-East part of Bulgaria has been established (Shindrova, 2006). A number of major resistance genes have been either identified in cultivated sunflower or introduced from wild Helianthus annuus or other wild 
Helianthus species (Miller, 1992). In our experiment we prove that $100 \%$ stable resistance of the sunflower mutant lines to downy mildew (race 330) can also be obtained through induced mutagenesis, in particular by treating immature zygotic embryo with ultrasound. The control genotype $381 \mathrm{R}$ is susceptible to this disease. The same mutation was obtained in all variations of this treatment of the initial genotype $381 \mathrm{R}$. This allows us to assume that there are mutable locations in the cultural sunflower genome resulting from induced mutagenesis. Although induced mutagenesis is a random and unpredictable process, there is an invaluable fact that the occurred mutation of resistance to downy mildew race 330 is of stable inheritance in the progenies of the fertility restorer lines $\left(\mathrm{R}_{5} \mathrm{M}_{5}\right.$ generation).

The hybrids No. 2 , No. 5 , No. 6 , No. 15 , No. 16 and No. 17 , produced with the participation of mutant lines $97 \mathrm{R}, 100 \mathrm{R}$ and $101 \mathrm{R}$ were $100 \%$ resistant to race 330 of downy mildew. The sterile analogues 1672 and 1676 were susceptible to this disease. The results allow us to conclude that the resistance of the mutant sunflower lines to downy mildew occurred as a result of a single gene dominant mutation. According Miller, 1992 and Vear et al., (2000) resistance to downy mildew is controlled by single dominant gene noted $\mathrm{Pl}$ and it has been found for all known races.

Broomrape presents serious problems to sunflower production in Bulgaria, as well. The area in which it grows is constantly expanding, forming new more virulent

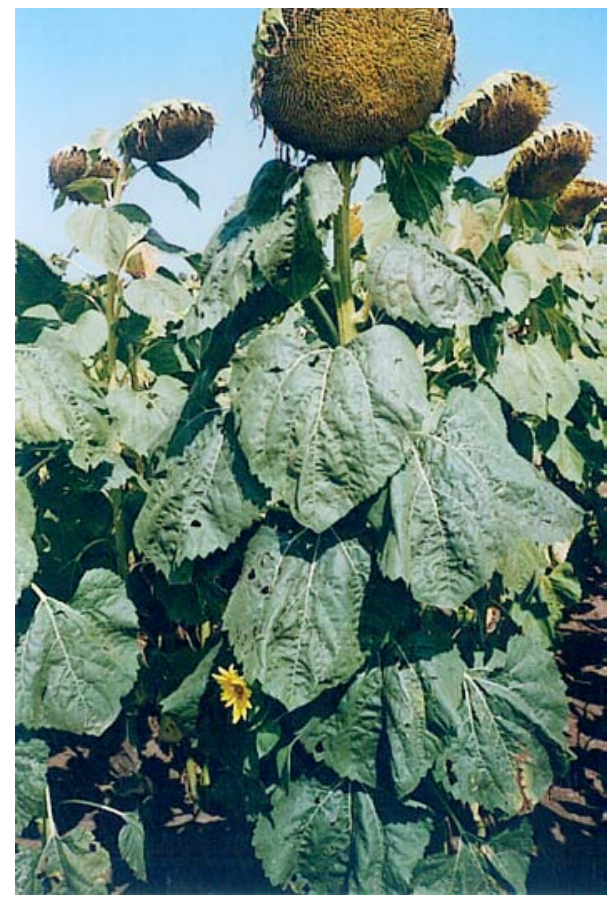

Figure 5: Hybrid No. 17 composed of line ms1676 and mutant line $101 \mathrm{RM}$ races (Shindrova, 1994). The phytopathological evaluation of the control genotype $381 \mathrm{R}$ and all the obtained mutant lines performed with regard to the local Orobanche population (race AE) show $100 \%$ resistance. Resistance to the parasite broomrape is of stable inheritance in the progenies of the fertility restorer lines $97 \mathrm{RM}, 98 \mathrm{RM}, 99 \mathrm{RM}$, $100 \mathrm{RM}$ and $101 \mathrm{RM}$. These results were confirmed during two years of evaluation.

The phytopathological evaluation of the hybrids produced with the participation of mutant lines $97 \mathrm{R}, 100 \mathrm{R}$ and 101 $\mathrm{R}$ shows $100 \%$ resistance to broomrape. The sterile analogues 1672 and 1676 were susceptible to this parasite.

As a result of our study we produced new sunflower restorer lines with good agronomic traits, resistance to downy mildew race 330 and preserving the best character of the control line 381 R-resistance to broomrape. 
A - Possibility for practical use of the hybrids No. 2, No. 5, No. 6, No. 15, No. 16 and No. 17, produced with the participation of mutant lines 97 RM, 100 RM and 101 RM

One-year testing of lines $97 \mathrm{R}, 100 \mathrm{R}$ and $101 \mathrm{R}$ showed 100\% restoration ability and very good combining ability. The sterile analogue of the Bulgarian self-pollinated line 1672 was used as a tester of the hybrids No. 2, No. 5 and No. 6, and 1676 for the hybrids No. 15, No. 16 and No. 17 (Figure 5). A one-factor dispersion analysis of hybrids (Figures 6-8) was carried out with regard to the seed and oil yield, as well as plant height.

The seed yield (Figure 6) of hybrids No. 2, No. 5, No. 6 produced during a oneyear period of testing mutagenic lines $97 \mathrm{R}, 100 \mathrm{R}$ and $101 \mathrm{R}$ exceeded the mean of standards (commercial hybrids San Luka, Maritza and Mura) by $2.4 \mathrm{~kg} / \mathrm{dka}$ to 52.1 $\mathrm{kg} / \mathrm{dka}$ but the results were not statistically significant. The same line testing on the line 1676 (hybrids No. 15, No. 16 and No. 17) has a positive and significant increase of the mean value of seed yield by 79.9 to $89.2 \mathrm{~kg} / \mathrm{dka}$ or $22.0 \%$ to $24.5 \%$ higher than the mean standard.

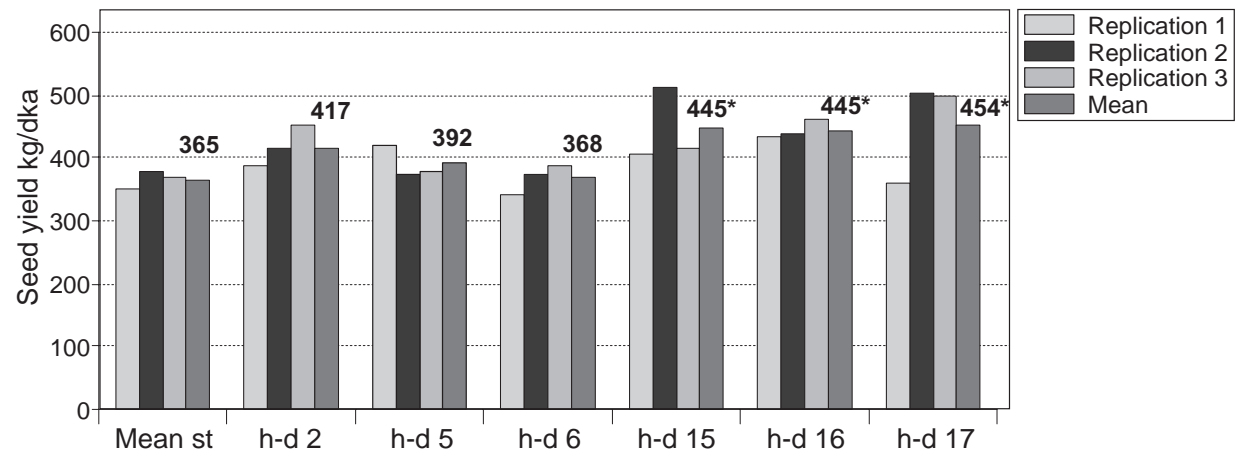

Figure 6: Seed yield (kg/dka) from hybrids 2, 5, 6, 15, 16 and 17 and the mea standard (commercial hybrids San Luka, Maritza and Mura) during 2006 ( ${ }^{*}-P=5 \%$ )

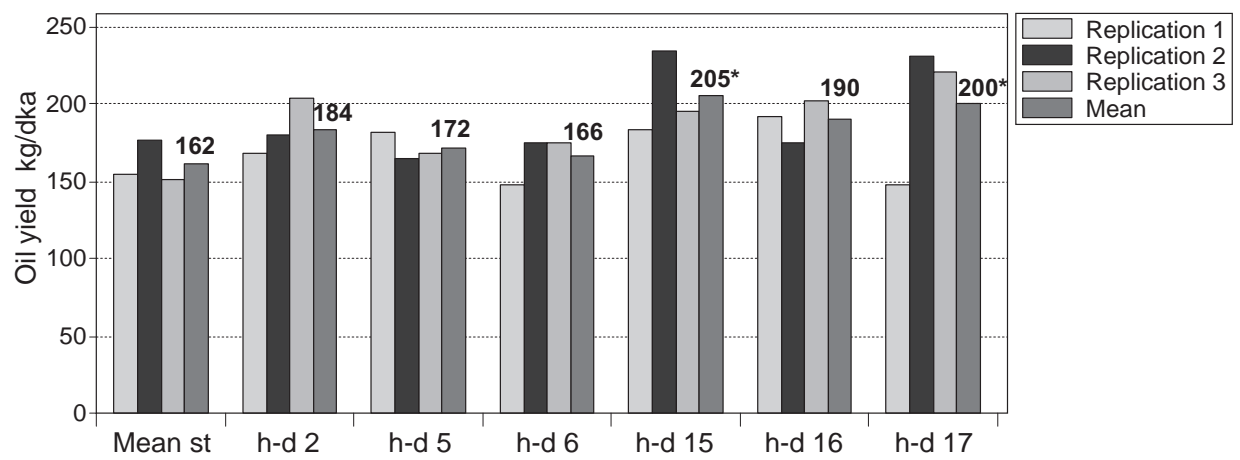

Figure 7: Oil yield ( $\mathrm{kg} / \mathrm{dka}$ ) from hybrids 2, 5, 6, 15, 16 and 17 and the mean standard (commercial hybrids San Luka, Maritza and Mura) during 2006 ( ${ }_{-} P=5 \%$ ) 
Oil yield is another important index. Figure 7 presents data on the investigated hybrids. The results from dispersion analysis of oil yield demonstrated that the difference according to the mean standard varied from $4 \mathrm{~kg}$ to $43 \mathrm{~kg}$ or $2.5 \%$ to $26.5 \%$. Significant increasing was registered only in hybrids No. 15 and No. 17.

Besides their higher seed and oil yields, the hybrids were characterized by statistically significant changes in the characteristic plant height. The results include both positive and negative deviation (Figure 8).

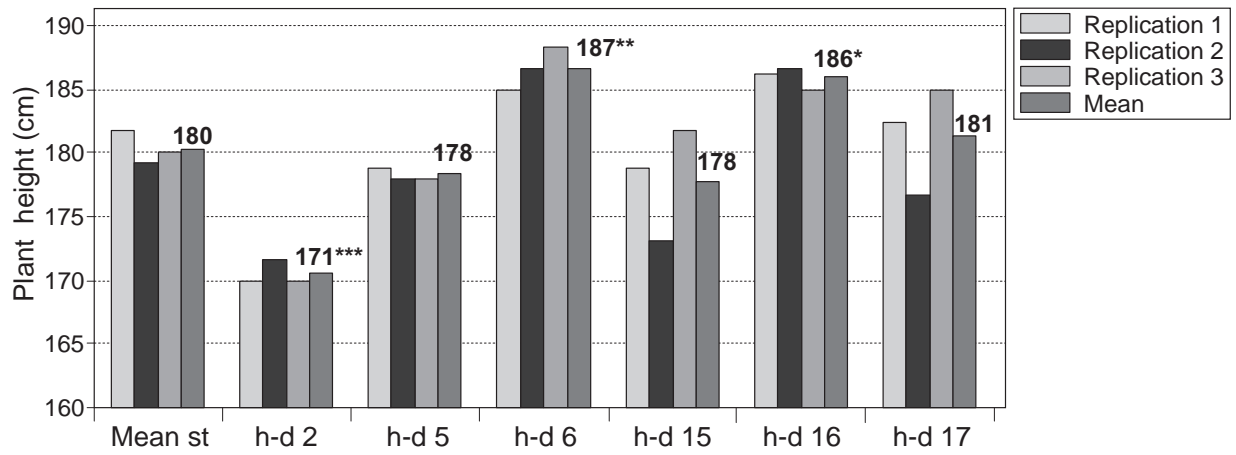

Figure 8: Plant height (cm) of hybrids 2, 5, 6, 15, 16 and 17 and the mean standard (commercial hybrids San Luka, Maritza and Mura) during 2006 ( ${ }^{*} P=5 \%$, ** $P=1 \%$, *** $P=0.1 \%$ )

A statistically significant decrease of plant height, which is $9 \mathrm{~cm}$, was observed in the hybrid No. 2. Such a change is especially important for mechanized harvesting of sunflower. Increase in this index in hybrids No. 16 and No. 6 was significantly higher by 6 and $7 \mathrm{~cm}$, respectively.

The newly developed hybrids No. 15, No. 16 and No. 17 were characterized by increased seed and oil yield, resistance to downy mildew race 330 and to the parasite broomrape, which is a desirable combination in the sunflower breeding programs.

\section{CONCLUSION}

Following the main problems of sunflower breeding at DAI, morphological, biochemical and phytopathological variability was developed by treatment with ultrasound. Combining induced mutagenesis in immature zygotic embryo with the embryo culture method, it can be assumed that the new variability obtained is only due to the effect of the mutagen. This assumption is confirmed by the fact that the embryo culture method alone does not generate variation due to the lack of mutagen factors in the nutrition medium and the short period of in vitro cultivation of the immature zygotic embryos. The advantage in this case is that this allows isolation of embryos before terminating their development and their planting onto nutrition medium to grow in vitro seedlings. 
We succeeded in creating mutant sunflower lines with increased oil content in seed and reduced height, and to obtain mutation for resistance to Plasmopara halstedii race 330, as well as in preserving one very important feature of the control line 381 R-resistance to broomrape. The use of ultrasound for the occurrence of single mutants controlled by one or several genes while preserving other positive characters of a control line is one of the most useful application of this technique.

Reduction of plant height, increasing oil content in seeds, very good combining ability, resistance to downy mildew and to the parasite broomrape of the new mutant lines is a desirable combination in the breeding program of sunflower.

The available literature on sunflower does not provide data on treatment of immature zygotic embryos with ultrasound. In this respect the approach is especially valuable due to the fact that immature sunflower zygotic embryos are treated at an early stage of development, i.e., this is functional tissue. This is expected to increase the frequency of mutations to a higher rate in comparison to a traditional approach of treating dry seeds. The fact that similar changes occurred in several immature embryos of the same control genotype $381 \mathrm{R}$ suggests that the same mutable regions were affected in the sunflower genome through induced mutagenesis.

Ultrasound in combination with embryo culture method offer plant breeders choices for production of desired variations and the ability to obtain 5 generations within a single year.

Although induced mutagenesis is a random and unpredictable process, it results in a genetically inheritable variation in sunflower breeding that is suitable to be used in the breeding program for production of new breeding materials and highly productive hybrids.

\section{REFERENCES}

Albourie, J.M., Tourvieille, J. and Tourvieille de Labrouhe, D. 1998. Resistance to metalaxil in isolates of the sunflower pathogen Plasmopara halstedii. European Journal Plant Pathology 104: 235-242.

Ahloowalia, B.S., 1990. In vitro radiation induced mutagenesis in potato. In: Sangwan, R.S. and Sangwan-Norreel, R.S. [Eds]. The Impact Biotechnology in Agriculture. Kluwer academic Publisher, Dordrecht, pp. 39-46.

Ashri, A., 1993. Mutation breeding in oil crops. In: M. Maluszynski and A. Ashri [Eds]. Report of the First FAO/IAEA Seminar on the use of Induced Mutagenesis and related Biotechnology for Crop Improvement for the Middle East and the Mediterranean region. IAEA, Vienna, pp. 82-94.

Azpiroz, I.S., Vincourt, P., Serieys, H. and Gallais, A., 1988. La culture in vitro des embryous immatures dans l'acceleration du cycle de selection des lignees de tournesol et ses effects morphovegetatifs. Helia 10: 35-38.

Baldini, M., Danuso, F., Turi, M., Sandra, M. and Raranciuc, S., 2006. Downy mildew (Plasmopara halstedii) infection in higt oleic sunflower hybris in northern Italy. Helia 45: 19-30.

Barov, V. and Shanin, J., 1965. Metodika na polskia opit, Sofia.

Berretta de Berger, A.M. and Miller, J.F., 1985. Estudio genetico de seis fuentes de estatura reducida de planta en girasol. In: Proc. $11^{\text {th }}$ Int. Sunflower Conf., Mar del Plata, Argentina. 10-13 March. Int. Sunflower Assoc. Toowoomba. Qld. Australia, pp. 651-657. 
Cheng, X.Y., Gao, M.W., Ling, Z.Q. and Lin, K.Z., 1990. Effect of mutagenic treatments on somaclonal variation in wheat (Triticum aestivum L.). Plant Breeding 105: 47-52.

Elliott, D.F. and Rao, K.R., 1982. Fast transforms: algorithms, analyses, applications. New York: Academic Press, 82-92.

Encheva, J., Ivanov, P., Tsvetkova, F. and Nikolova, V., 1993. Development of a new initial breeding material in sunflower (Helianthus annuus L.) using direct organogenesis and somatic embryogenesis. Euphytica 68: 181-185.

Encheva, J., Tsvetkova, F. and Ivanov, P., 2002. Creating genetic variability in sunflower through the direct organogenesis method, independently and in combination with gamma irradiation. Helia 25(37): 85-92.

Encheva, J., Christov, M., Nenov, N., Ivanov, P. and Encheva, V., 2003. Genetic variability of sunflower (Helianthus annuus L.) created by combination of polycross hybridization and ultrasonic or gamma irradiation. Bulgarian Journal of Agricultural Science Vol. 9(3): 321-327.

Encheva, J., Tsvetkova, F. and Ivanov, P., 2003. A comparison between somaclonal variation and induced mutagenesis in tissue culture of sunflower line Z-8-A (Helianthus annuus L.). Helia 26(38): 91-98.

Encheva, J., Kohler, H., Friedt, W., Tsvetkova, F., Ivanov, P., Encheva, V. and Shindrova, P., 2003. Field evaluation of somaclonal variation in sunflower (Helianthus annuus L.) and it's application for crop improvement. Euphytica 130: 167-175.

Encheva, J., Christov, M. and Ivanov, P., 2004. Developing of B lines in sunflower (Helianthus annuus L.) by combined use of polycross method with ultrasound and embryo culture method. Bulgarian Journal of Agricultural Science Vol. 10(3): 281-290.

Everett, B.S., 1984. An introduction to latent variable models. London: Chapman \& Hall. 125132.

Fick, G.N., 1978. Sunflower breeding and genetics. In: Carter, J.F. [Ed.], Sunflower science and technology. Agron. Monograph 19: 279-337.

Gamborg, O.L., Miller, R.A. and Ojima, K., 1968. Nutriment requirements of suspension cultures of soybean root cells. Exp. Cell Res. 50: 151-158.

Gavazzi, G., Tonelli, C., Todesco, G., Arreghini, E., Raffaldi, F., Vecchio, F., Barbuzzi, G., Biasini, M. and Sala, F., 1987. Somaclonal variation versus chemically induced mutagenesis in tomato (Licopersicum esculentum L.). Theor. Appl. Genet. 74: 733-738.

Gulya, T.J., Miler, J.F., Firanyi, F. and Sackston, W.E., 1991. Proposed internationally standardized method for race identification of Plasmopara halstedii. Helia 14: 11-20.

Maluszynski, M., Amano, E., Ahloowalia, B., Van Zanten, L. and Sigurbjornsson, B., 1994. Mutation techniques and related biotechnologies for rice improvement. In: Seventh Meeting of the International Program on Rice Biotechnology, May 1994, Bali, The Rockefeller Foundation, New York, pp. 294.

Maširević, S., 1992. Rase prouzrokovača plamenjače suncokreta (Plasmopara halstedii) kod nas i u svetu. University of Novi Sad, Faculy of Agriculture. Periodicals of Institute of Field and Vegetable Crops Novi Sad, 20: 405-407.

Mouzeyar, S., Phillipon, J., Walser, P., Vear, F. and Tourvieille de Labrouhe, D., 1994. Sunflower resistance to French races of downy mildew (Plasmopara halstedii). Agronomie 14: 335-336.

Molinero-Ruiz, L., Domingues, J., Melero Vara, J.M., 2000. Evaluation of Spanish isolates of Plasmopara halstedii for tolerance to metalaxil. Helia 23: 33-38.

Miller, J.F. and Hammond, J.J., 1991. Inheritance of reduced height in sunflower. Euphytica 53: $131-136$.

Miller, J.F., 1992. Update on inheritance of sunflower characteristics. In: Proc. $13^{\text {th }}$ Int. Sunflower Conf., Sept. 7-11, Pisa, Italy, Vol. II, pp. 905-945.

Micke, A., Donini, B. and Maluszynski, M., 1990. Induced mutation for crop improvement Mutat. Breed. Rev. 7: 1-41.

Murashige, T. and Skoog, F., 1962. A revised medium for rapid growth and bioassays with tobacco tissues cultures. Plan. Physiol. 15: 473-497.

Newport Instrument Ltd., 1972. Use of the Newport quantity analyzed as a replacement for solvent extraction for measuring the oil and fat content of oil seeds, chocolate, meat and other material. Newport Pagnell, England.

Novak, F.J., Daskalov, S., Brunner, H., Nestincky, M., Afza, R., Dolezelova, M., Lucretti, S., Herichova, A. and Hermelin, T., 1988. Somatic embryogenesis in maize and comparison 
of genetic variability induced by gamma radiation and tissue culture techniques. Plant Breeding 101: 66-79.

Novak, F.J., Afza, R., van. Duren, M. and Omar, M.S., 1990. Mutation induction by gamma irradiation of in vitro cultured shoot-tips of banana and plantain (Musa cvs). Trop. Agric. 67(1): 21-28.

Panchenko, A.N., 1975. An early diagnostic method for resistance to Orobanche cumana Wallr. Agricultural newspaper 2: 225-228 (in Russian).

Shindrova, P., 1994. Distribution and race complex of Broomrape (Orobanche cumana Wallr.) in Bulgaria. Proceedings of the Third International Workshop on Orobanche and Striga Research, Amsterdam, pp. 142-145.

Shindrova, P., Ivanov, P. and Nikolova, V., 1998. Effect of broomrape (Orobanche cumana Wallr.) intensity of attack on some morphological and biochemical indices of sunflower (Helianthus annuus L.). Helia 21, No 29: 55-62.

Shindrova, P., 2006. Downy mildew (Plasmopara halstedii) (Farl. Berlese et de Tony)distribution and race composition during 2004-2005. $70^{\text {th }}$ Anniversary of Plant Protection Institute and Annual Balkan Week of Plant Health. Plant Protection Institute, May 28-31. Kostinbrod, Bulgaria, pp. 22. 
